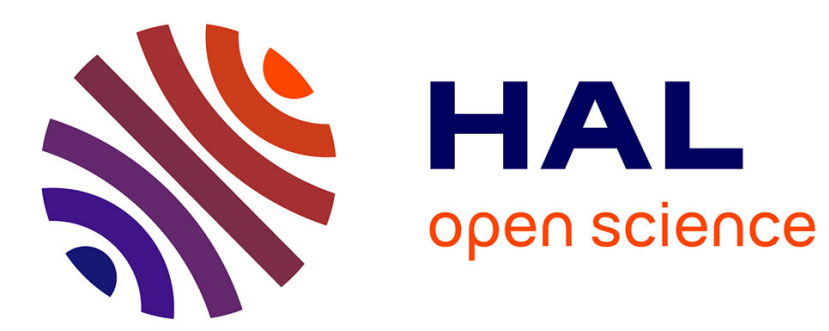

\title{
The Nordic Model and the Oil Nation
}

Roberto Iacono

\section{- To cite this version:}

Roberto Iacono. The Nordic Model and the Oil Nation. 2016. hal-01402143

\section{HAL Id: hal-01402143 \\ https://hal.science/hal-01402143}

Preprint submitted on 24 Nov 2016

HAL is a multi-disciplinary open access archive for the deposit and dissemination of scientific research documents, whether they are published or not. The documents may come from teaching and research institutions in France or abroad, or from public or private research centers.
L'archive ouverte pluridisciplinaire HAL, est destinée au dépôt et à la diffusion de documents scientifiques de niveau recherche, publiés ou non, émanant des établissements d'enseignement et de recherche français ou étrangers, des laboratoires publics ou privés. 


\title{
The Nordic Model and the Oil Nation*
}

\author{
Roberto Iacono ${ }^{\dagger}$
}

September 1, 2016

This paper investigates the long-run economic effects of large natural resource endowments, through a comparative quantitative case study. Focusing on three economic features of the so-called Nordic model, namely low income inequality, high labour productivity growth, and high welfare spending, this study estimates the shocks to these key features in Norway after the country became one of the world's largest oil exporters. A synthetic control unit constructed by weighting Nordic countries that resemble the economy of Norway without being oil producers provides the most reliable comparison unit to estimate the causal effects constituting the paper's threefold contribution. First, results show that the resource windfall contributed to relatively higher top income shares, adding natural resources to the set of drivers of income inequality in Norway. Second, the resource windfall boosted labour productivity. Third, resource revenues contributed to financing the steadily increasing gap between Norway and other Nordic countries in the degree of welfare generosity. Sensitivity tests through in-time placebo tests and difference-in-differences estimations confirm the validity of these results.

JEL codes: E02, H53, I38, Q33.

Key words: Nordic model, Resource windfall, Synthetic Control Method.

*I am grateful for comments and suggestions from Rolf Aaberge, Jonathon Moses, Paolo Piacquadio, Nicholas Sheard, Chiara Ravetti, Rune Skarstein. I am also grateful for valuable remarks from participants of the 18th INFER and of the 31st EEA-ESEM annual conferences.

${ }^{\dagger}$ Norwegian University of Science and Technology, Department of Applied Social Science (FHS), NO7491, Trondheim, Norway, roberto.iacono@ntnu.no 


\section{INTRODUCTION}

The aim of this research is to econometrically estimate the response of three economic features of the so-called Nordic model (namely low income inequality, high productivity growth and high welfare spending) for Norway, after the country became one of the world's largest oil exporters. In other words, this paper provides a quantitative comparative case study which can highlight the robustness of the key features of the Nordic model when subjected to a substantial structural shock. In doing so, this paper complements previous studies with a similar methodology, such as Mideksa (2013) and Larsen (2006), which analyze the impact of the resource windfall, focusing mostly on the Norwegian GDP per capita.

The supposed exceptionality of the Nordic model has been analyzed, questioned, and tested by scholars (among others, Lane et al., 1993) with regard to a variety of aspects, with egalitarianism of the wealth distribution getting the most attention. Fochesato and Bowles (2015) attempted to measure the relative egalitarian performance of the Nordic economies by comparing their level of material wealth inequality with respect to a large group of economies over the past three thousand years. Their conclusion is that the Nordic economies do not produce a more egalitarian distribution of material wealth than, for example, some horticultural and forager economies, although they show a higher level of intergenerational and social mobility. Barth et al. (2014, 2015) provide a theoretical overview of the main political and economic features of the Nordic open economies, summarizing and putting together results from previous economic research on the issue: Moene et al. (1993), Moene and Wallerstein (1997) and Barth et al. (2013).

This research follows Barth et al. (2014) in representing the Nordic model as a set of three distinct but interconnected mechanisms. These are: $(i)$ collective bargaining which leads to labour wage compression (i.e., high minimum wages and low maximum wages) through a combination of central wage negotiations and local wage negotiations at the firm level; (ii) high labour productivity which, combined with wage compression, stimulates high private investments and creation of new highly productive enterprises; (iii) political support for large ratios of public welfare spending to GDP. The scope of the present study is to briefly review and empirically test the robustness of each of these mechanisms, by comparing Norway to the other Nordic economies.

In order to observe a wholly hypothetical counterfactual, the treatment (i.e., the resource windfall) would ideally impact only a unit or a subgroup of the four Nordic economies 
(i.e., Norway, Denmark, Finland and Sweden) representing the full sample of this study. For this reason, the donor pool provided by the untreated countries represents the perfect sample in order to construct a counterfactual that matches the treated country. The countries of Denmark, Finland and Sweden, resembling the economy of Norway without being oil producers ${ }^{1}$, therefore provide the most reliable donor pool of comparison units. The Synthetic Control Method (SCM, hereafter) is implemented to assign weights to the countries of the donor pool, in order to obtain a synthetic control unit that is subsequently used to estimate the causal effects constituting the paper's threefold contribution.

First, results show that the windfall contributed to a lower degree of wage compression, measured by higher top income shares relative to the Nordic neighbors. This finding adds natural resources to the set of variables that explain the increase in income inequality in Norway documented in the economic literature, and summarized in Aaberge and Atkinson (2010).

Second, the treatment boosted labour productivity, regardless of the increased income inequality. This covariation of increased inequality and boosted productivity after the shock is not predicted by the theoretical model in Barth et al. (2014), which implies that a lower degree of wage compression would slow down the dynamic process of creative destruction and hence lead to lower labour productivity in the end.

Third, results indicate that the treatment contributed to financing a steadily increasing gap in the degree of welfare generosity ${ }^{2}$ between Norway and the other Nordic countries, with an increase in generosity in Norway. Again, this result is not in line with the prediction that overall welfare generosity in Norway should decrease in response to a higher level of income inequality; that prediction is based on the political reinforcement hypothesis in Barth et al. (2015), although their model relies on the assumption of a given exposure to the risk of income losses, which is no longer the case when the resource sector is taken into account. The result of an increasing gap in the overall degree of welfare generosity post-treatment can be explained by the volatile income streams in the resource sector, which increase individuals' exposure to the risk of income losses and hence foster the voters' preferences for public spending and welfare generosity. In addition, resource revenues enlarged the

1. Figure 1 in Corak (2013) shows that the four Nordic economies of Norway, Sweden, Denmark and Finland have in common a remarkably low level of income inequality (measured as the Gini coefficient) jointly with a high degree of intergenerational economic mobility (measured as the elasticity between parental and children's earnings).

2. Generosity scores for social insurance programs in the four Nordic countries are derived from the Comparative Welfare Entitlements Data Set in Scruggs (2014) and Scruggs et al. (2014). 
tax base through the post-treatment years, allowing the Norwegian government to finance a sustained level of overall welfare generosity. Sensitivity tests through in-time-placebo tests and difference-in-differences estimations have been conducted throughout the paper, in order to confirm the validity of these results.

The paper proceeds as follows: Section 2 presents the windfall that accrued to the Norwegian economy, Section 3 analyzes the causal effects on the labour market and on income inequality, Section 4 presents the effects on productivity and private investments, whilst Section 5 focuses on the effects on public welfare spending. Section 6 provides concluding remarks.

\section{THE RESOURCE WINDFALL}

This paper considers the jump in Norway's total production of petroleum above the substantial threshold of 50 million standard cubic meter $\left(\mathrm{Sm}^{\wedge} 3\right)$ oil equivalents (i.e., including oil, condensate, NGL and gas), which happened in 1980, as the treatment; this was the start of the oil adventure that caused a structural change in the Norwegian economy without substantially affecting the other Nordic countries ${ }^{3}$. Figure 1 plots the yearly production of oil equivalents on the Norwegian continental shelf, 1971 - 2014, as reported by the Norwegian Petroleum Directorate.

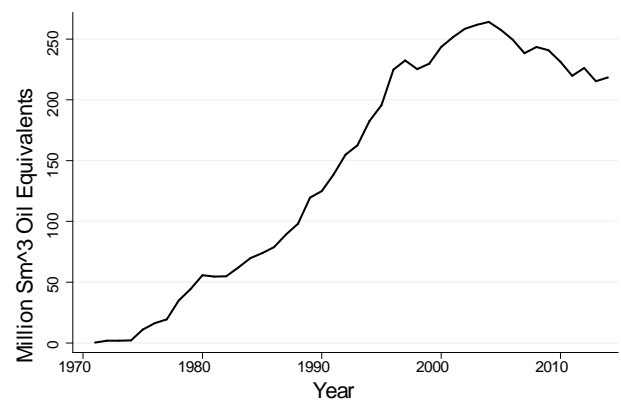

Figure 1 - Total production of oil equivalents on the Norwegian continental shelf, 1971-2014. Source: The Norwegian Petroleum Directorate

3. Mideksa (2013) estimated the causal comparative effect of natural resource endowment on the level of the Norwegian GDP per capita. Results in Mideksa (2013) show that about $20 \%$ of the Norwegian annual GDP per capita increase in the post-windfall period $1971-2007$ can be attributed to the petroleum endowment. 
Although extraction started as early as 1971, as plotted in Figure 1, the fact that the impact of extraction on income and GDP did not significantly appear until a few years later (as documented in Bjørnland, 1998; Larsen, 2006; and Mideksa, 2013), contributes to justify the choice of the treatment year.

The intuition behind the empirical analysis of this paper is that becoming a main oil exporter significantly modifies the structure and performance of labour market institutions that determine income inequality, productivity and investments, as well as public welfare spending through higher resource revenues. The research question then becomes: did oil extraction and the related structural changes determine a new path for the Norwegian economy (measured by three main mechanisms), significantly different from those of her Nordic neighbors? Whether the answer is affirmative or negative, the results of this paper offer additional empirical evidence on the Nordic model's relevance as an analytical framework.

\section{LABOUR MARKET AND INCOME INEQUALITY}

The economic literature related to the dispersion of wage earnings, income inequality and labour market institutions (summarized in the survey by Salverda and Checchi, 2013), introduces the context for the first empirical exercise of this paper: how has the oil windfall impacted the wage structure and more broadly the degree of income inequality in Norway, compared to the Nordic neighbors?

First, I will provide some predictions by applying the model in Barth et al. (2014) to the current context with a booming resource sector. An initial high degree of wage compression attracts foreign companies due to the lower upper bound they will be able to offer to highskilled labour in the oil sector, as compared to the hypothetical upper bound for the same high-skilled worker in other countries. This leads ceteris paribus to higher expected profits for the representative extracting company and hence boosts investment opportunities. In turn, increased labour demand in the resource sector of the economy causes a jump in the whole range of resource sector wages, which is not fully reflected in the wages of the rest of the economy due to institutional constraints, at least at first ${ }^{4}$. Hence, this determines a lower degree of wage compression in the labour force as a whole after the treatment and, for given capital incomes, higher top income shares (considered as a key driver of

4. This wage inflation mechanism in the Norwegian resource sector which reduces the overall degree of wage compression has been closely analyzed in Dyrstad (2015). 
total income inequality, and given by sum of labour and capital incomes, excluding capital gains $^{5}$ ). Note that substantial upward wage adjustments for high-skilled workers might also be justified in case of perfect mobility of labour in the oil sector across countries, leading to the above-mentioned jump in the whole range of resource sector wages ${ }^{6}$.

Some caveats about the identifying assumption (i.e., the fact that no other important factors but the expansion of the resource sector have impacted the treated unit) are relevant here. The causal effect of the treatment on top income inequality in Norway, which will be estimated below, might also be partially explained by additional factors that are not related to the treatment, such as tax reforms and the deregulation of financial markets (through their effects on capital income). Aaberge and Atkinson (2010), for instance, identify the implementation of the 1992 Norwegian tax reform as a decisive factor leading to a sharp increase in capital income (dividends and capital gains) received by households, which in turn boosted inequality of the income distribution. In order to partially take into account these possible limitations, the dependent variable considered in the analysis below will be given by top income shares excluding capital gains. Another question is to what extent the liberalization of financial markets, which created strong incentives to shift labour income to capital income, was an exclusive feature of the Norwegian economy compared to the Nordic neighbors. Bjorklund et al. (1995) estimated that Sweden also experienced a significant increase in income inequality in the period 1989 - 1991 due to a boost in capital gains that resulted from changes in the tax legislation. For Finland, Riihelä et al. (2008) claim that the increase in inequality at the high end of the income distribution observed over the period 1990 - 2004 can be seen as a consequence of the 1993 Finnish tax reform which introduced the so-called Nordic dual income tax model. Similar tax reforms took place in Denmark in 1994, as highlighted in Fritzell et al. (2011). Hence, to the extent that these changes in financial and tax legislation in Scandinavia did not exclusively concern the Norwegian economy, they do not seem to invalidate the identifying assumption of this paper.

5. A methodological discussion about whether and how high top income shares translate into high concentration of power can be found in Aaberge et al. (2013).

6 . The causal effect of treatment on unemployment rates can be ambiguous but it will not be explicitly tested in this study. On the one hand, boosted labour demand in the resource sector might reduce unemployment rates with respect to the neighboring countries, although this positive could be mitigated or even canceled by migration flows from the other Nordic countries to Norway. On the other hand, the uncertain resource income due to high variance of the resource price for oil might lead to lower investments at times and hence relatively higher unemployment rates. 


\section{III.A. The first empirical exercise}

The SCM has been implemented in Abadie et al. (2010), Abadie et al. (2011) and Abadie et al. (2015), in order to estimate the causal effect of policies or shocks, as the difference between the outcome for the actual treated unit and the predicted outcome of the synthetic control unit, constructed by weighting the units of the donor pool. The aim of this exercise is to apply the SCM in order to test whether the prediction of higher top income shares for Norway $(j=1)$ is confirmed by the data. As noted above, the donor pool of potential comparison units $(j=2, . ., 4)$ includes Denmark, Finland and Sweden, which are assumed to resemble the series of income inequality in Norway before the treatment.

Define top $5 \%$ income shares (excluding capital gains) ${ }^{7}$ as the dependent variable $Y$ for country $j=1, \ldots, 4$. A set of $k$ determinants of the dependent variable $Y$ are included in the analysis as predictors, namely: UTIP-UNIDO industrial pay-inequality ${ }^{8}$; Top $1 \%$ income share (excluding capital gains); Unemployment rate; Trade Union Density (TUD, details in Data Appendix); and real GDP per capita (constant 2005 USD). For each unit, the predictors are observed throughout the time range 1960 - 2009 and constitute a balanced panel. The entire time range is divided into a pre-treatment $1960-1979$ and a posttreatment period $1980-2009$, in order to estimate the causal effect of the treatment on post-treatment top income shares. Define $\Pi_{1}$ as the $(k \times 1)$ matrix containing the pretreatment values of the predictors for the treated unit, whilst $\Pi_{0}$ is the $(k \times 3)$ matrix containing the pre-treatment values of the three comparison units. Following Abadie et al. (2011) and Abadie et al. (2015), the synthetic control unit is given by the convex combination of weights $W^{*}=\left(w_{2}, w_{3}, w_{4}\right)$ with $w_{2}+w_{3}+w_{4}=1$, chosen in order to minimize the weighted sum of the squared differences $\sum_{m=1}^{k} v_{m}\left(\Pi_{1 m}-\Pi_{0 m} W\right)^{2}$, in which $v_{m}$ represents the relative importance of each predictor ${ }^{9}$.

The implementation of the SCM assigns the following weights to the countries of the

7. The time series of wage dispersion $(d 9 / d 1)$ would also qualify as a relevant dependent variable for this exercise; however, data for the whole time range of this empirical exercise $(1960-2009)$ were not available.

8. UTIP-UNIDO industrial pay-inequality (further details in the Data Appendix) is an indicator of industrial wage dispersion and hence can be considered as a good proxy for top income shares, thereby contributing to the efficacy of matching the treated and synthetic control unit in the pre-treatment period.

9. Kaul et al. (2016) advice not to use all pre-treatment outcomes as predictors in the analysis, claiming that using all outcome lags as separate predictors renders all other covariates irrelevant. I followed the prescription by Kaul et al. (2016) in this empirical exercise. 
donor pool ${ }^{10}$ :

\begin{tabular}{|c|c|}
\hline Country & Synthetic control weights $W^{*}$ \\
\hline Denmark & 0 \\
\hline Finland & .272 \\
\hline Sweden & .728 \\
\hline
\end{tabular}

Hence, the synthetic control unit is a linear combination of two countries of the donor pool, specifically Finland (0.272) and Sweden (0.728). The zero weight assigned to Denmark is not sufficient to justify the exclusion of this country from the donor pool, for two reasons. First, dropping a zero weight country a posteriori does not improve the quality of the estimation. Secondly, a zero weight only means that the specific country is relatively less powerful in resembling the predictors of the treated unit in the pre-treatment country. More generally (and differently from an OLS regression), a synthetic weight indicates the explanatory power of a unit relative to others, rather than its absolute explanatory power ${ }^{11}$.

Define $Y_{j t}$ as the top $5 \%$ income shares for country $j=1, \ldots, 4$ at time $t$. The weights presented in (1) can then be used to construct the synthetic control unit given by $\sum_{j=2}^{4} w_{j}^{*} Y_{j t}$, which will be compared to the post-treatment dependent variable of the actual treated unit $Y_{1 t}$. In other words, the difference $Y_{1 t}-\sum_{j=2}^{4} w_{j}^{*} Y_{j t}$ will represent the estimation of the causal effect of the treatment (i.e., Norway becoming an oil nation) on the treated unit's posttreatment values of the top $5 \%$ income shares (excluding capital gains). The series of the top $5 \%$ income shares for both the treated and the synthetic unit are plotted in the following Figure 2:

10. The averaged values for each of the predictors, for both the treated unit and the synthetic unit, can be found in Table 2 in the appendix. Further details about the algorithm of the Synthetic Control Method can be found in Abadie et al. (2011) and Abadie et al. (2015). The statistical software package "Synth" is available online at http://stanford.edu/ jhain/software.htm\#Synth

11. In order to observe a study in which most of the units included in the construction of the synthetic unit receive a zero weight, see Abadie et al. (2010), page 500, Table 2. 


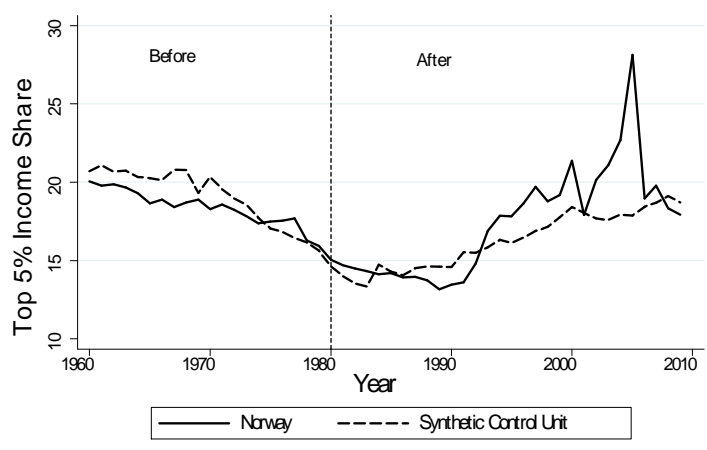

Figure 2 - The effect of the intervention on Top 5\% Income Share

Figure 2 shows several noteworthy trends. Firstly, top 5\% income shares for the Nordic countries seem to have a common declining trend up to the mid-1980s (declining from a $20 \%$ share to slightly below 15\%), and an increasing trend from then onward. In the matching period, the solid line for Norway does not show a significantly different development from that of the synthetic unit, which hence successfully resembles the treated unit and allows us to turn to the analysis of the right hand side of the 1980 line in Figure 2. From the treatment onward, the top $5 \%$ income share for Norway displays higher values for the entire period $1992-2008$ and, more generally, substantially higher volatility ${ }^{12}$.

This result seems to confirm the qualitative predictions of higher income inequality described above, although the magnitude of this increased inequality is on average within an income share of 5\%. To what extent can this result partly be explained by the 1992 Norwegian tax reform? As explained above, tax reforms from the $1990 \mathrm{~s}$ do not in principle invalidate the identifying assumption because they were contemporaneously implemented in all the countries constituting the sample of this study. However, it cannot be excluded that the same tax reform had a different effect on the capital income component of the top income shares, causing a stronger jump in income inequality for Norway. In any case, the results of this empirical exercise can be seen as complementary to the analysis in Aaberge and Atkinson (2010), because they add the booming resource sector to the group of explanatory variables underlying the actual jump in Norwegian income inequality (both in absolute terms as in Aaberge and Atkinson, 2010, and with respect to the Nordic neighbors as in the current study).

When it comes to robustness checks, a weakness of the SCM is that no confidence

12. As documented in Aaberge et al. (2013), the exceptionally high peak of top income shares in 2005 is due to the anticipation of a new tax on dividends introduced in 2006 by the Norwegian tax authorities. 
intervals are produced in order to test the statistical power of the synthetic unit. However, robustness checks can be done by conducting in-time placebo tests and more traditional difference-in-differences exercises. In-time placebo tests consist of reassigning the treatment to a year before or after the large increase in oil extraction activity actually took place in Norway. In the case of a treatment year earlier than 1980 - for example, 1970 - the shorter pre-treatment period over which predictors are averaged might result in a less powerful set of synthetic weights. These in-time placebo tests were conducted for different treatment years both before and after 1980; they validate the main results of Figure 2 by showing no significant changes in the predictive power of the synthetic control unit ${ }^{13}$.

In order to provide more robustness checks, a standard difference-in-differences exercise was conducted:

$$
T o p 5 \%_{j, t}=\gamma_{j}+\delta_{t}+\lambda T_{j, t}+X_{j, t}^{\prime} \beta+\epsilon_{j, t}
$$

where $T o p 5 \%_{j, t}$ stands for the top $5 \%$ income share of country $j ; \gamma_{j}$ is a country fixed effect; $\delta_{t}$ represents a dummy variable estimating time fixed effects; $T_{j, t}$ is a dummy variable which equals one when the country under observation is the treated country (i.e., Norway) and the time of observation is within the post-treatment period $1980-2009 ; X_{j, t}^{\prime}$ includes a set of covariates (details in Table 3 in the appendix); and $\epsilon_{j, t}$ are country-clustered error terms. The OLS estimate of the coefficient $\lambda$ will then represent the difference-in-differences estimator of the causal effect of the treatment.

As shown in Table 3 (in the appendix), the difference-in-differences estimator $\lambda$ of the causal effect of oil production on top income shares for Norway does not reject the main results of Figure 2; neither does it provide additional insights. The coefficient $\lambda$ is positive, although weakly significant when controlling for key labour market features of the Nordic countries - for instance, trade union density.

What does the treatment, combined with this result of slightly increased income inequality, imply for the series of productivity and investments in Norway compared to her Nordic neighbors? This question is addressed in the following section.

13. Results are available in the appendix, and are shown in Figures $2 a$ and $2 b$. 


\section{Productivity and investments}

How does a booming resource sector in Norway influence the path of innovation, productivity, and investments, compared to the other Nordic countries? We begin with a straightforward prediction of the direct effect of the treatment on private investments and productivity growth. The booming resource sector initially implies huge capitalist investments and creation of new enterprises, hence boosting private investments for Norway relative to the other Nordic countries. These new, high value-added enterprises in the resource sector imply a substantial jump in productivity levels.

However, there is also an indirect channel. In their theory of creative destruction and wage compression, Barth et al. (2014) emphasize that a high initial degree of wage compression might function as a tax on low-productivity firms (due to the high salaries for low-skilled human capital) and as a subsidy for high-productivity firms (due to the low salaries for high-skilled human capital), leading to higher expected profits for the high-productivity firms, and hence fostering innovation and new investments through the Schumpeterian process of "constructive" creative destruction. In turn, new private investments raise the demand for labour and the equilibrium wages for a constant employment level. More importantly, this process leads to a higher number of workers employed in high-productivity firms, which implies an overall higher average level of labour productivity.

Now, how does this positive wage compression-productivity multiplier (analyzed in the absence of shocks) work in the context of this study? Given the result of the first empirical

exercise above (i.e., higher income inequality in Norway), the prediction is that Norway should jump to an equilibrium with lower productivity and weaker innovation capacity, compared to the other Nordic countries. Will this indirect negative effect counterbalance the above mentioned positive direct effect of the treatment on the level of Norwegian productivity?

\section{IV.A. The second empirical exercise}

At first, let us observe the development of productivity in the four Nordic countries in Figure 3, measured in GDP per hour worked (constant 2010 USD, PPPs) from 1970 to 2014, as reported by the OECD. 


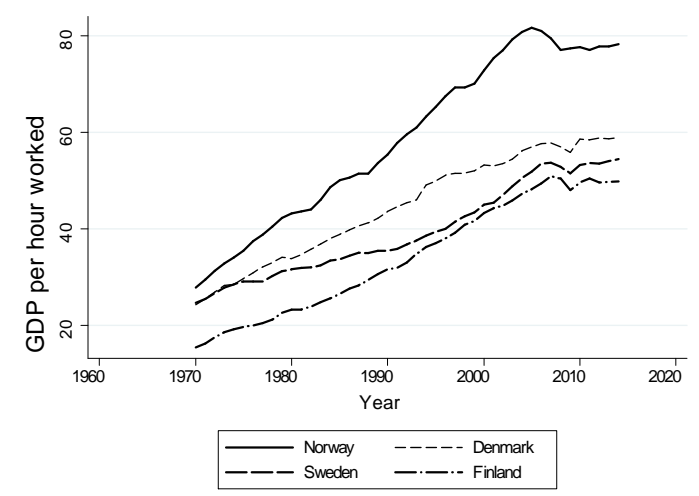

Figure 3 - The development of labour productivity

As can be seen from Figure 3, the development of labour productivity for Norway strictly dominates that of the other Nordic countries, starting from a higher initial level in 1970 and increasing at a faster rate throughout the next decades. This evidence calls for a different approach to that used in the first empirical exercise. No possible synthetic weight assigned to the countries of the donor pool would closely match the series of Norwegian labour productivity in the pre-treatment period. At first sight, the direct effect of treatment on GDP per hour worked appears stronger than the countervailing negative indirect channel through income inequality described above. However, in order to provide some empirical results to back up this intuition, a traditional difference-in-differences exercise was carried out by estimating:

$$
Y h_{j, t}=\theta_{j}+\rho_{t}+\mu N_{j, t}+\Omega_{j, t}^{\prime} \phi+\epsilon_{j, t}
$$

in which $Y h_{j, t}$ is defined as the real GDP per hour worked $(1970-2014$, constant 2010 USD, PPPs) for country $j ; \theta_{j}$ is a dummy estimating countries' fixed effects; $\rho_{t}$ is a dummy estimating time fixed effects; $N_{j, t}$ is the interaction dummy which equals one if and only if the country under observation is the treated country (i.e., Norway) and the time of observation is within the post-treatment period $1980-2009 ; \Omega_{j, t}^{\prime}$ includes a set of conventional covariates (gross capital investments, education expenditure and gross savings); and $\epsilon_{j, t}$ are error terms adjusted for country clustering. The OLS estimate of the coefficient $\mu$ will once again represent the difference-in-differences estimator of the effect of treatment. 
As shown in Table 4 (in the appendix), in Norway, the treatment causes a jump of 6 to 12.5 USD (constant 2010 USD, PPPs) in GDP per hour worked, which is statistically significant as well. In other words, the take-home message from this exercise confirms that the supposed indirect negative effect of the treatment on productivity via increased income inequality is outweighed by the positive boost to average productivity induced by private investments in the resource sector. To the extent that these preliminary results can be generalized, the findings of slightly increased income inequality and boosted productivity after the shock do not seem to go in the same direction of the positive wage compression labour productivity multiplier of Barth et al. (2014).

The third and last contribution of this study looks at the third element of the Nordic model framework analyzed in Barth et al. (2014): the political economy of public welfare spending. How does the treatment impact the relative growth of welfare spending in Norway and other Nordic countries? To what extent can the above empirical results of increased income inequality and boosted productivity help us to predict this growth?

\section{Public Welfare SPENDing}

The focus of this section will be on the Nordic countries as providers of public services and social insurance, as for instance unemployment and sickness insurance, health expenditure and pensions. How does a booming resource sector in Norway influence the growth of welfare spending relative to its Nordic neighbors? In other words, does the structural change implied by the treatment, jointly with the higher income inequality observed above, imply a shift to less or more welfare generosity in Norway?

At first, let us briefly review the recent literature. The Nordic model benchmark described in Barth et al. (2014) and Barth and Moene (2015) predicts that wage compression might boost productivity and raise average wages, which in turn leads to increased demand for welfare spending and a shift to the left (i.e., higher welfare generosity) of the entire political spectrum. Let us see in more detail how this happens. In Barth et al. (2014) and Barth and Moene (2015), both income level and the marginal benefit of public services determine the voter's preferences for welfare spending. The authors show that, for a given exposure to the risk of income loss, higher income (i.e., higher equilibrium wage induced by higher average labour productivity) increases the demand for welfare spending (i.e., welfare spending is assumed to be a normal good). This is due to the fact that, as voters become richer, the income loss associated with a less generous welfare state gets larger, whilst the 
utility cost necessary to finance welfare programs gets smaller. Hence, these modified preferences move both the right and left political parties toward a new equilibrium with a more generous welfare state. Barth et al. (2015) focus on changes in the income distribution (for a given mean income) and the consequent shift in preferences for generous welfare spending. They hypothesize that, for voters below the mean, an increase in income inequality reduces their willingness to finance welfare, hence leading to a shift toward the political right and less welfare generosity; they label this the political reinforcement hypothesis.

To what extent will these theoretical predictions appear in the results of the third empirical exercise? It has to be pointed out that the empirical analysis below does not aim at precisely testing the predictions of the above models, for a straightforward reason. The results of Barth et al. (2014, 2015) and Barth and Moene (2015) build on the assumption of a given exposure to the risk of income losses in absence of shocks, which does no longer hold when the treatment is defined to be the volatile booming resource sector of Norway.

To summarize, the causal relationship between treatment and welfare generosity estimated in the following empirical exercise might confirm either one of the following predictions: $(i)$ treatment causes higher degree of wage dispersion and income inequality, less demand for social insurance and in turn a lower overall degree of welfare generosity (as in Barth et al.,2014, 2015; and Barth and Moene, 2015); (ii) a booming resource sector with high but volatile income streams increases the exposure to the risk of income loss, and hence increases support for public spending and a high overall degree of welfare generosity. Which one of these effects prevails in the third empirical exercise?

\section{V.A. The third empirical exercise}

The set-up of this last empirical exercise resembles the first one, with Norway $(j=1)$ being the treated unit and the donor pool of potential comparison units $(j=2, . ., 4)$ consisting of Denmark, Finland and Sweden, which are assumed to resemble the overall welfare generosity for Norway before the treatment.

The implementation of the SCM is also technically similar to the first empirical exercise, but with a new dependent variable and predictors. The data set collected for this exercise comes from the Comparative Welfare Entitlements Data Set in Scruggs et al. (2014), which contains annual country data $(1971-2010)$ on the provision of the main three social insurance programs: unemployment insurance, sick pay insurance, and public pensions.

For each of these three main areas, Scruggs et al. (2014) contains data on replacement 
rates for individuals and families, program coverage and a program generosity index (with a numerical score from 0 to 25). In addition, Scruggs (2014) sums up the three program indices to compute a combined generosity index, which is the $Z$ dependent variable of the exercise below. The maximum theoretical score for this combined index is 75 , namely the sum of the three program scores. Additional details on calculation of replacement rates and program generosity indices can be found in Scruggs (2014).

A set of $n$ determinants of the dependent variable $Z$ are included in the analysis as predictors, namely: program generosity indices (unemployment, sickness and pension); replacement rates: single (100\% earnings) (unemployment, sick pay and standard pension); replacement rates: family (100\% earnings) (unemployment, sickness and standard pension); program coverage: (\% of the labor force insured for unemployment risk, $\%$ of the labor force with sick pay insurance, portion of those above official retirement age who are in receipt of a public pension). For each country, these predictors are observed throughout the time range $1971-2010$ in order to form a strongly balanced panel. The treatment year is 1980, as in the previous exercises.

The SCM now assigns the following weights to the countries of the donor pool ${ }^{14}$ :

\begin{tabular}{|c|c|}
\hline Country & Synthetic control weights $W^{*}$ \\
\hline Denmark & 0 \\
\hline Finland & .275 \\
\hline Sweden & .725 \\
\hline
\end{tabular}

Quite similarly to the weights assigned in the first empirical exercise, Finland counts for $(0.275)$ whilst Sweden is (0.725) in the synthetic control unit. Once again, Denmark is assigned a zero weight, which is, however, not sufficient to justify its exclusion from the donor pool, for the reasons described above. More interestingly, the similar weights obtained for completely different predictors not only prove that Sweden provides a better match with Norway, but also show the overall robustness of these weights. Let us proceed now with the computation of the difference $Z_{1 t}-\sum_{j=2}^{4} w_{j}^{*} Z_{j t}$ which will represent the estimation of the causal effect of the treatment on the treated unit's post-treatment values of the combined generosity index, measuring the generosity of the welfare state. The series of the combined generosity index for both the treated and the synthetic unit are plotted

14. The averaged values for each of the predictors, for both the treated unit and the synthetic unit, can be found in Table 5 in the appendix. 
in Figure 4:

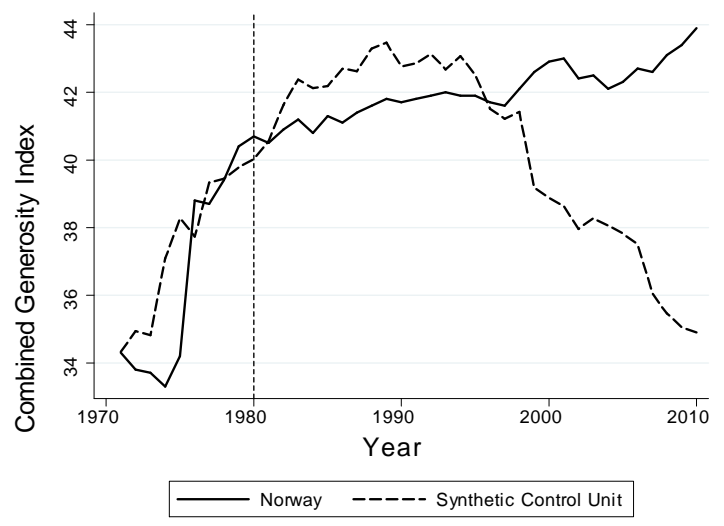

Figure 4 - The effect on the Combined Welfare Generosity Index

At first, the left hand side (before 1980) of Figure 4 highlights that the synthetic control unit matches the dynamics of the combined generosity index series for Norway (however weakly than in the case of the first empirical exercise), thereby allowing to turn to the analysis of the causal effect of the treatment, on the right hand side of Figure 4. The u-shaped series of the synthetic control unit shows that, from the 1990s onward, the synthetic control unit unambiguously declines toward roughly the same level of combined generosity as in 1971, hence marking a sharp reduction in welfare generosity (more precisely, a reduction of more than $50 \%$ with respect to the level of the index in 1990). On the other hand, the combined generosity index for Norway steadily increases until 2010, showing a structurally different trend.

It is relevant to issue certain caveats here, when it comes to the economic interpretation of this result. As is the case for a causal inference analysis conducted through the SCM, in which there is no need to select and precisely measure the treatment, other decisive factors might have contributed to the result shown in Figure 4, as for instance political reforms of social insurance programs unrelated to the treatment. However, and to the extent that we can claim that the gap in welfare generosity observed in Figure 4 has been fostered by the huge resource revenues received by Norway from the $1980 \mathrm{~s}$ onward, the intuition behind this result is the following. There is no evidence of decreased overall welfare generosity in Norway in response to a higher level of income inequality, as predicted for instance by the political reinforcement hypothesis in Barth et al. (2015). More likely, the volatile income streams of the resource sector increased the exposure to the risk of income loss, which can 
in turn boost the voters' preferences for public spending and welfare generosity. On the fiscal revenue side, resource revenues enlarged the tax base through the post-treatment years, allowing the Norwegian government to finance a constantly growing level of overall welfare generosity.

Before turning to the concluding remarks, a few robustness checks for this last empirical exercise should be mentioned. In-time placebo tests were conducted here as well, for different treatment years throughout the range of years 1985 - 1990, with no significant changes in the predictive power of the synthetic control unit ${ }^{15}$. In addition, and for the sake of consistency with the previous empirical exercises, a more traditional difference-indifferences estimation was set up:

$$
C G I_{j, t}=\eta_{j}+\nu_{t}+\pi D_{j, t}+\Psi_{j, t}^{\prime} \varphi+\epsilon_{j, t}
$$

in which $C G I_{j, t}$ is defined as the score of the combined generosity index of welfare programs $(1971-2010)$ for country $j ; \eta_{j}$ and $\nu_{t}$ estimate respectively countries' fixed effects and time fixed effects; $D_{j, t}$ is a dummy for the interaction of the treated country with the post-

treatment period; $\Psi_{j, t}^{\prime}$ includes a set of covariates (replacement rates and program coverage for each of the three programs); and $\epsilon_{j, t}$ are error terms adjusted for country clustering.

As shown in Table 6 (in the appendix), the difference-in-differences estimator of the causal effect of the treatment on the combined generosity index, represented by the coefficient $\pi$, is positive and is significant in most of the regressions with controls. This confirms the main result of increased overall welfare generosity in Norway in response to the treatment.

\section{CONCluding Remarks}

How has a large natural resource windfall impacted income inequality, labour productivity and welfare spending in Norway? This was the aim of this research, which econometrically estimates the development of the three main economic features of the so-called Nordic model for the case of Norway, after the country became one of the world's largest oil exporters. The identifying assumption relies on the fact that Denmark, Finland and Sweden, which jointly resemble the economic outcomes of Norway, are not oil producers; hence they provide the most reliable donor pool of comparison units.

15. Results are available in the appendix, and are shown in Figures $4 a$ and $4 b$. 
The main results are summarized as follows, together with some considerations for future research. The first empirical exercise showed that the windfall contributed to a lower degree of wage compression in Norway, measured by slightly higher top income shares relative to the Nordic neighbors. However, the magnitude of this effect is not large, and hence shows the need for further research employing different indicators of wage dispersion and income inequality. Still, this finding makes a contribution by adding resource revenues to the set of factors explaining the increased income inequality in Norway that has been documented in Aaberge and Atkinson (2010). Secondly, increased private investments in the high value-added resource sector clearly boosted labour productivity, despite the increased income inequality. The relevance of this otherwise predictable finding is that the covariation between increased inequality and boosted productivity does not coincide with the theoretical prediction of the model in Barth et al. (2014), in which lower wage compression would slow down the dynamic process of creative destruction and hence labour productivity. Here, as well, further (empirical and theoretical) research is needed to further investigate the mechanisms at work. Thirdly, results show that the streams of resource revenues induced a steadily increasing gap in the degree of welfare generosity (measured by the combined generosity index) in which Norway's generosity pulled ahead of the other Nordic countries. More importantly, this finding is again not in the line with the in-equality multiplier of Barth et al. (2015), predicting a decreased overall welfare generosity in Norway in response to a higher level of income inequality. As highlighted in the paper, other decisive factors might also have contributed to this third result, as for instance political reforms in public service provision and social insurance programs. More research at both the individual and cross-country levels is therefore needed. Regardless of the possibility of confounding factors, the result of the third empirical exercise clearly shows no evidence of decreased overall welfare generosity in Norway. Instead, the results support the testable hypothesis that a windfall of resource revenues enlarged the tax base, allowing the Norwegian government to finance a sustained level of overall welfare generosity. 


\section{A Data Appendix ${ }^{16}$}

- Top income shares: top income shares for the four Nordic countries $(1960-2011)$ were retrieved from The World top Incomes Database, and are based on Atkinson and Søgaard (2012), Jäntti et al. (2010), Aaberge and Atkinson (2010), Roine and Waldenström (2010). Data extracted on 17 Sep 2015.

- UTIP-UNIDO industrial pay inequality: industrial pay-inequality data (19632008) are available from the University of Texas Inequality Project (UTIP) at http://utip.gov.utexas.edu/data.html. The data set constitutes a panel comprised of the between-groups component of Theil's $T$ statistic (fully described in Conceição et al., 2000) measured in different countries across a stable and consistent set of industrial sectors. Data extracted on 17 Sep 2015.

- Unemployment: unemployment rates, as a \% of Labour Force (1960 - 2013), were collected from the OECD Labor Force Statistics. Data extracted on 17 Jun 2015.

- Trade Union Density (TUD): TUD corresponds to the ratio of wage and salary earners that are trade union members, divided by the total number of wage and salary earners (1960 - 2013, OECD Labour Force Statistics). OECD (2015): Density is calculated using survey data, wherever possible, and administrative data adjusted for non-active and self-employed members otherwise. Data extracted on 17 Jun 2015.

- GDP per hour worked: GDP per hour worked (1970 - 2014, constant 2010 USD, PPPs). doi: 10.1787/1439e590-en (Accessed on 23 September 2015). OECD (2015): GDP per hour worked is a measure of labour productivity. It measures how efficiently labour input is combined with other factors of production and used in the production process. Labour input is defined as total hours worked of all persons engaged in production.

- Gross fixed capital formation: Gross fixed capital formation (1966 - 2014, constant 2005 USD). Data from database: World Development Indicators. WDI (2015): Gross fixed capital formation includes land improvements (fences, ditches, drains, and so on); plant, machinery, and equipment purchases; and the construction of

16. The Stata dataset file .dta and the file .do written for this paper are available from the author upon request. 
roads, railways, and the like, including schools, offices, hospitals, private residential dwellings, and commercial and industrial buildings. Data extracted on 24 Sep 2015.

- Gross capital formation: Gross capital formation (1970 - 2014, constant 2005 USD). WDI (2015): Gross capital formation consists of outlays on additions to the fixed assets of the economy plus net changes in the level of inventories. Data from database: World Development Indicators. Data extracted on 24 Sep 2015.

- Education expenditure: education expenditure as a \% of GNI (1970 - 2013). WDI (2015): education expenditure refers to the current operating expenditures in education, including wages and salaries and excluding capital investments in buildings and equipment. Data from database: World Development Indicators. Data extracted on 25 Sep 2015.

- Gross savings: gross savings as a \% of GNI (1970-2013). WDI (2015): gross savings are the difference between gross national income and public and private consumption, plus net current transfers. Data from database: World Development Indicators. Data extracted on 25 Sep 2015.

- Program generosity scores: calculation of the program generosity sub-indices (1971 - 2010, unemployment, sickness and pension) is explained in detail in Scruggs (2014). Data are extracted from Scruggs et al. (2014).

- Replacement rates: as explained in the CWED codebook in Scruggs, Detlef and Kuitto (2014), "replacement rates are calculated for a fictive average production worker in the manufacturing sector who is 40 years old, has been working for the 20 years preceding the loss of income or the benefit period". $1971-2010$. Single: 100\% earnings, living alone, no children or other dependents. Family: 100\% earnings, cohabiting with a dependent spouse with no earnings, two children aged 7 and 12 . Data are extracted from Scruggs et al. (2014).

- Program coverage: program coverage $(1971-2010, \%$ of the labor force insured for unemployment risk, $\%$ of the labor force with sickpay insurance, portion of those above official retirement age who are in receipt of a public pension). Data are extracted from Scruggs et al. (2014). 
- GDP per capita: GDP per capita constant 2005 USD (1960 - 2014) was obtained from the World Bank's World Development Indicators. Data extracted on 15 Sep 2015 .

- Total production of petroleum: yearly production of oil equivalents (oil, NGL and condensate, million $\mathrm{Sm}^{\wedge} 3$ ) on the Norwegian continental shelf, $1971-2014$. Updated: 29.09.2015. Source: The Norwegian Petroleum Directorate. 


\section{REFERENCES}

Aaberge R., Atkinson A.B., "Top Incomes in Norway", Chapter 9 in Atkinson, A. B. and Piketty, T. (editors) "Top Incomes: A Global Perspective", Oxford University Press, 2010.

Aaberge R., Atkinson A.B. and J. Modalsli, "The ins and outs of top income mobility", Discussion Papers Statistics Norway Research department, No. 762, 2013.

Abadie A., Diamond A., Hainmueller J., "Synthetic Control Methods for Comparative Case Studies: Estimating the Effect of California's Tobacco Control Program", Journal of the American Statistical Association, 105(2010): 493-505. doi: 10.1198/jasa.2009.ap08746

Abadie A., Diamond A., Hainmueller J., "Synth: An R Package for Synthetic Control Methods in Comparative Case", Journal of Statistical Software, 42(2011): 1-17.

Abadie A., Diamond A., Hainmueller J., "Comparative Politics and the Synthetic Control Method", American Journal of Political Science 59(2015): 495-510.

Alvaredo F., A.B. Atkinson, T. Piketty and E. Saez. The World Top Incomes Database. http://topincomes.g-mond.parisschoolofeconomics.eu/

Atkinson A.B., Søgaard J.E., "The long-run history of income inequality in Denmark. Top Incomes from 1870 to 2010", Mimeo, 2012.

Barth, E., Finseraas H., Moene, K.O., Nilsen, K.M., "Social insurance vs. redistribution", Mimeo, Institute for Social Research, 2013.

Barth E., Moene K.O., F. Willumsen, "The Scandinavian model - An interpretation", Journal of Public Economics, 117(2014): 60-72.

Barth, E., Finseraas H., Moene K.O., "Political reinforcement: how rising inequality curbs manifested welfare generosity", American Journal of Political Science, 59(2015): 565577 .

Barth, E., Moene, K., "The Equality Multiplier: How Wage Compression and Welfare Empowerment Interact", Journal of the European Economic Association (JEEA), forthcoming, 2016. DOI: 10.1111/jeea.12163

Bjorklund A., M. Palme, I. Svensson, "Tax Reforms and Income Distribution: An Assessment Using Different Income Concepts", Swedish Economic Policy Review, 2(1995), 229-66.

Bjørnland H.C., "The Economic Effects of North Sea Oil on the Manufacturing Sector", Scottish Journal of Political Economy, 45 (1998), pp. 553-585.

Conceição P., P. Ferreira and J. Galbraith, "The Young Person's Guide to the Theil Index: Suggesting Intuitive Interpretations and Exploring Analytical Applications", University of Texas Inequality Project Working Paper No. 14, 2000, March.

Corak M., "Income Inequality, Equality of Opportunity, and Intergenerational Mobility", Journal of Economic Perspectives, 27(2013): 79-102. 
Dyrstad, J.M., "Resource curse avoidance: Governmental intervention and wage formation in the Norwegian petroleum sector", Department of Economics Working Paper Series No.6/2015, Norwegian University of Science and Technology.

Fochesato M., S. Bowles, "Nordic exceptionalism? Social democratic egalitarianism in world-historic perspective", Journal of Public Economics, 127 (2015), 30-44.

Fritzell J., O. Backman, V.M. Ritakallio, "Income inequality and poverty: do the Nordic countries still constitute a family of their own?", in Jon Kvist, Johan Fritzell, Bjorn Hvinden, Olli Kangas (editors) "Changing social equality: The Nordic welfare model in the 21st century", Policy Press, University of Bristol, 2011.

Jäntti M., Riihelä M., Sullström R. and Tuomala M., "Trends in Top Income Shares in Finland", chapter 8 in Atkinson, A. B. and Piketty, T. (editors) "Top Incomes: A Global Perspective", Oxford University Press, 2010.

Kaul A., Klossner S., Pfeifer G. and M. Schieler, "Synthetic Control Methods: Never Use All Pre-Intervention Outcomes as Economic Predictors", Working paper (2015), University of Hohenheim.

Lane J.E., Martikainen T., Svensson P., Vogt G. and Valen H., "Scandinavian exceptionalism reconsidered", Journal of Theoretical Politics, 5(1993): 195-230.

Larsen E.R., "Escaping the Resource Curse and the Dutch Disease? When and Why Norway Caught Up with and Forged Ahead of Its Neighbors", American Journal of Economics and Sociology 65 (2006): 605-640.

Mideksa T.K., "The economic impact of natural resources", Journal of Environmental Economics and Management, 65(2013): 277-289.

Moene, K.O., Wallerstein, M., Hoel, M., "Part II: bargaining structure and economic performance". In: Flanagan, R.J., Moene, K.O., Wallerstein, M. (Eds.), "Trade Union Behaviour, Pay Bargaining and Economic Performance". Clarendon Press, Oxford, 1993.

Moene, K.O., Wallerstein, M., "Pay inequality", Journal of Labor Economics, 3(1997): 403-430.

Riihelä M., R. Sullström \& I. Suoniemi, "Tax Progressivity and Recent Evolution of the Finnish Income Inequality", Discussion Papers 460, Government Institute for Economic Research Finland (VATT), 2008.

Roine J., Waldenström D., "Top Incomes in Sweden over the Twentieth Century", Chapter 7 in Atkinson, A. B. and Piketty, T. (editors) "Top Incomes: A Global Perspective", Oxford University Press, 2010.

Salverda W. and D. Checchi, "Labour-Market Institutions and the Dispersion of Wage Earnings", Discussion Paper No. 8220, The Institute for the Study of Labor (IZA), 2014, May.

Scruggs L., Detlef J. and K. Kuitto, "Comparative Welfare Entitlements Dataset", 2. Version 2014-03. University of Connecticut \& University of Greifswald. Available at: http://cwed2.org/. 
Scruggs L., "Social Welfare Generosity Scores in CWED 2: A Methodological Genealogy", CWED working paper series no.1, University of Connecticut \& University of Greifswald, 2004.

Scruggs L., Detlef J. and K. Kuitto, "Comparative Welfare Entitlements Dataset 2 Codebook", Version 2014-03. University of Connecticut \& University of Greifswald, 2014. 


\section{B Tables and figures}

Table 1 - Descriptive statistics and variable descriptions.

\begin{tabular}{llll}
\hline Variable description & Data Source & Mean & Std. Dev. \\
\hline Top5\% Income share, excl. capital gains & World Top Incomes Database & 17.906 & 2.9616 \\
Top1\% Income share, excl. capital gains & World Top Incomes Database & 6.371 & 1.8374 \\
Industrial pay-inequality & UTIP-UNIDO & 0.007 & 0.0028 \\
TUD-Union members, \% of wage earners & OECD Labor Force Statistics & 66.308 & 11.1696 \\
Unemployment rate, \% of labour force & OECD Labor Force Statistics & 4.620 & 3.2355 \\
GDP per capita, constant 2005 USD & World Development Indicators & 33831.6 & 13972.7 \\
GDP per hr. worked, constant 2010 USD & OECD Productivity Statistics & 44.05 & 15.9021 \\
Gross fixed capital, mill. constant 2005 USD & World Development Indicators & 44946.64 & 20161.09 \\
Gross capital, mill. constant 2005 USD & World Development Indicators & 49000.64 & 20461.49 \\
Education expenditure, \% of GNI & World Development Indicators & 5.9733 & 0.996 \\
Gross savings, \% of GNI & World Development Indicators & 27.4696 & 4.5409 \\
Unemployment generosity score & CWED & 10.558 & 2.426 \\
Sick pay generosity score & CWED & 14.924 & 2.056 \\
Pension generosity score & CWED & 12.693 & 1.403 \\
Unemployment replacement rate (single) & CWED & 0.662 & 0.124 \\
Sick pay replacement rate (single) & CWED & 0.806 & 0.155 \\
Pension replacement rate (single) & CWED & 0.569 & 0.086 \\
Total prod. of oil equivalents, mill. Sm^3 & Norwegian Petroleum Direct. & 145.015 & 94.324 \\
\hline
\end{tabular}


Table 2: Predictor Means before treatment for Treated and Synthetic Unit

\begin{tabular}{lll}
\hline Predictor & Treated & Synthetic \\
\hline Industrial pay-inequality & 0.0083 & 0.0065 \\
GDP per capita, constant 2005 USD & 25063.09 & 19663.97 \\
Top5\% Income share & 18.379 & 19.107 \\
Top1\% Income share & 5.843 & 6.546 \\
TUD-Union members & 56.483 & 65.395 \\
Unemployment rate & 1.295 & 2.151
\end{tabular}

Note: predictors are averaged over the period $1960-1979$. 


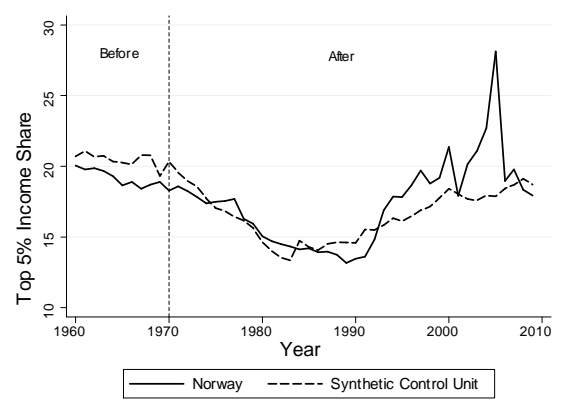

Figure $2 \mathrm{a}$

Note: figure $2 a$ shows in-time placebo test with treatment year 1970 .

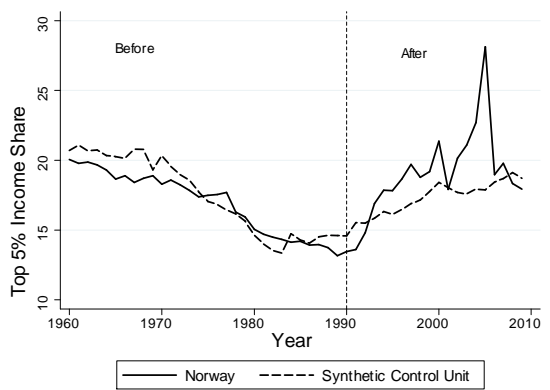

Figure 2b

Note: figure $2 b$ shows in-time placebo test with treatment year 1990 . 
Table 3: Dependent variable is the Top 5\% Income share.

\begin{tabular}{lcccc}
\hline & $(1)$ & $(2)$ & $(3)$ & $(4)$ \\
\hline \multirow{2}{*}{ Diff-in-Diff } & & & & \\
& $\mathbf{2 . 6 0 5}$ & $\mathbf{2 . 7 0 9 *}$ & $\mathbf{1 . 9 5 8}$ & $\mathbf{1 . 7 9 1}$ \\
Industrial pay-inequality & $\mathbf{( 0 . 9 4 3 )}$ & $\mathbf{( 0 . 9 0 6 )}$ & $\mathbf{( 1 . 1 9 7 )}$ & $\mathbf{( 0 . 9 9 4 )}$ \\
& & 2.373 & -51.22 & -1.947 \\
Trade Union Density & & $(273.7)$ & $(236.4)$ & $(180.4)$ \\
& & -0.0675 & $-0.0969^{* *}$ \\
Unemployment rate & & & $(0.0331)$ & $(0.0275)$ \\
& & & & 0.165 \\
Time FE & & & & $(0.206)$ \\
Country FE & YES & YES & YES & YES \\
Observations & YES & YES & YES & YES \\
R-squared & 207 & 180 & 180 & 180 \\
Number of countries & 0.779 & 0.762 & 0.774 & 0.783 \\
\hline
\end{tabular}

Note: robust standard errors adjusted for country clustering in parentheses. ${ }^{* * *} \mathrm{p}<0.01,{ }^{* *} \mathrm{p}<0.05,{ }^{*} \mathrm{p}<0.1$ 
Table 4: Dependent variable is GDP per hour worked (1970 - 2014, USD constant prices, 2010 PPPs)

\begin{tabular}{|c|c|c|c|c|c|}
\hline & (1) & $(2)$ & $(3)$ & (4) & (5) \\
\hline \multirow[t]{2}{*}{ Diff-in-Diff } & $12.46^{* *}$ & $12.47 * *$ & $10.15^{* *}$ & $10.02 * *$ & $6.353^{*}$ \\
\hline & $(1.844)$ & $(1.695)$ & $(1.188)$ & $(0.809)$ & (1.342) \\
\hline \multirow[t]{2}{*}{ Gross Fixed Capital } & & $-5.64 \mathrm{e}-11$ & $-6.31 \mathrm{e}-10^{*}$ & $-6.63 \mathrm{e}-10^{* *}$ & $-6.78 \mathrm{e}-10^{*}$ \\
\hline & & $(5.09 \mathrm{e}-11)$ & $(1.16 \mathrm{e}-10)$ & $(1.02 \mathrm{e}-10)$ & $(1.77 \mathrm{e}-10)$ \\
\hline \multirow[t]{2}{*}{ Gross Capital } & & & $5.76 \mathrm{e}-10^{*}$ & $6.16 \mathrm{e}-10^{* *}$ & $5.36 \mathrm{e}-10^{*}$ \\
\hline & & & $(1.09 \mathrm{e}-10)$ & $(1.04 \mathrm{e}-10)$ & $(1.19 \mathrm{e}-10)$ \\
\hline \multirow[t]{2}{*}{ Education exp. } & & & & 0.738 & 0.578 \\
\hline & & & & $(0.835)$ & (1.037) \\
\hline \multirow[t]{2}{*}{ Gross Savings } & & & & & 0.275 \\
\hline & & & & & $(0.162)$ \\
\hline Time FE & YES & YES & YES & YES & YES \\
\hline Country FE & YES & YES & YES & YES & YES \\
\hline R-squared & 0.969 & 0.969 & 0.974 & 0.973 & 0.970 \\
\hline Observations & 180 & 180 & 180 & 176 & 161 \\
\hline
\end{tabular}

Robust standard errors adjusted for country clustering in parentheses.

${ }^{* * *} \mathrm{p}<0.01,{ }^{* *} \mathrm{p}<0.05,{ }^{*} \mathrm{p}<0.1$ 
Table 5: Predictor Means before treatment for Treated and Synthetic Unit

\begin{tabular}{lll}
\hline Predictor & Treated & Synthetic \\
\hline Unemployment generosity score & 10.36 & 8.15 \\
Sick pay generosity score & 14.03 & 16.47 \\
Pension generosity score & 11.86 & 12.74 \\
Unemployment replacement rate (single) & 0.571 & 0.702 \\
Sick pay replacement rate (single) & 0.740 & 0.828 \\
Pension replacement rate (single) & 0.467 & 0.537 \\
Unemployment replacement rate (family) & 0.662 & 0.747 \\
Sick pay replacement rate (family) & 0.809 & 0.883 \\
Pension replacement rate (family) & 0.529 & 0.673 \\
Unemployment coverage & 0.802 & 0.615 \\
Sick pay coverage & 0.98 & 1 \\
Pension coverage & 0.995 & 1 \\
\hline
\end{tabular}

Note: predictors are averaged over the period $1971-1979$. 


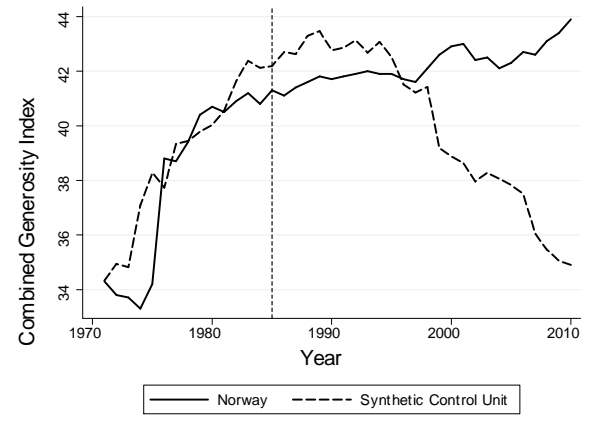

Figure 4a

Note: figure $4 a$ shows in-time placebo test with treatment year 1985 .

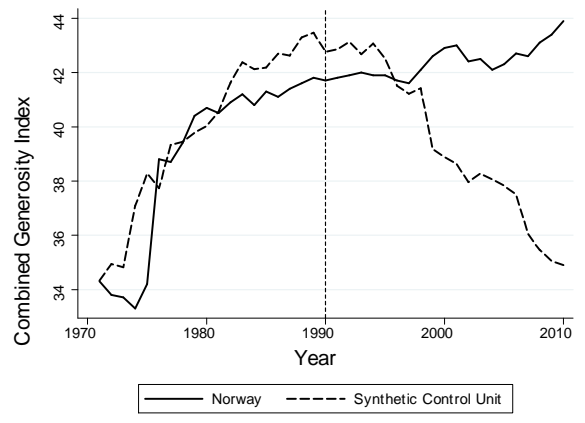

Figure $4 \mathrm{~b}$

Note: figure $4 b$ shows in-time placebo test with treatment year 1990. 
Table 6: Dependent variable is Combined Generosity Index

\begin{tabular}{|c|c|c|c|c|}
\hline & (1) & $(2)$ & $(3)$ & (4) \\
\hline Diff-in-Diff & $\begin{array}{c}2.369 \\
(1.488)\end{array}$ & $\begin{array}{c}3.611 * * \\
(0.843)\end{array}$ & $\begin{array}{c}1.487 * * \\
(0.462)\end{array}$ & $\begin{array}{c}1.565 * * \\
(0.392)\end{array}$ \\
\hline Unemp. repl. single & $\begin{array}{c}13.24 \\
(6.667)\end{array}$ & $\begin{array}{c}10.73^{* *} \\
(2.875)\end{array}$ & $\begin{array}{c}9.339 * * \\
(2.702)\end{array}$ & $\begin{array}{c}9.853^{* *} \\
(2.453)\end{array}$ \\
\hline Unemp. repl. family & $\begin{array}{l}-3.182 \\
(6.487)\end{array}$ & $\begin{array}{c}1.486 \\
(3.729)\end{array}$ & $\begin{array}{c}4.409 \\
(2.954)\end{array}$ & $\begin{array}{c}4.037 \\
(2.259)\end{array}$ \\
\hline Sick pay repl. single & $\begin{array}{c}9.095 \\
(7.542)\end{array}$ & $\begin{array}{c}14.03^{* * *} \\
(2.147)\end{array}$ & $\begin{array}{c}7.096 \\
(3.022)\end{array}$ & $\begin{array}{c}6.030 \\
(2.625)\end{array}$ \\
\hline Sick pay repl. family & $\begin{array}{l}-6.894 \\
(9.884)\end{array}$ & $\begin{array}{c}-8.898^{*} \\
(3.231)\end{array}$ & $\begin{array}{l}-0.324 \\
(3.619)\end{array}$ & $\begin{array}{c}0.769 \\
(3.171)\end{array}$ \\
\hline Pension repl. single & $\begin{array}{l}-14.61 \\
(7.651)\end{array}$ & $\begin{array}{c}-20.40^{* *} \\
(5.572)\end{array}$ & $\begin{array}{c}-16.40^{* *} \\
(4.211)\end{array}$ & $\begin{array}{c}-16.10^{* *} \\
(3.566)\end{array}$ \\
\hline Pension repl. family & $\begin{array}{c}24.81^{* *} \\
(5.225)\end{array}$ & $\begin{array}{c}25.58^{* * *} \\
(3.993)\end{array}$ & $\begin{array}{c}18.81^{* *} \\
(3.489)\end{array}$ & $\begin{array}{c}18.49 \text { *** } \\
(2.792)\end{array}$ \\
\hline Unemp. cov. & & $\begin{array}{c}16.06^{* * *} \\
(2.481)\end{array}$ & $\begin{array}{l}5.407^{*} \\
(2.247)\end{array}$ & $\begin{array}{l}5.726^{*} \\
(1.882)\end{array}$ \\
\hline Sick pay cov. & & & $\begin{array}{c}24.35^{* * *} \\
(4.041)\end{array}$ & $\begin{array}{c}24.32^{* * *} \\
(3.402)\end{array}$ \\
\hline Pens. cov. & & & & $\begin{array}{l}7.163^{*} \\
(3.027)\end{array}$ \\
\hline Time FE & YES & YES & YES & YES \\
\hline Country FE & YES & YES & YES & YES \\
\hline R-squared & 0.893 & 0.931 & 0.970 & 0.971 \\
\hline Observations & 159 & 159 & 159 & 158 \\
\hline
\end{tabular}

Robust standard errors adjusted for country clustering in parentheses.

$* * * \mathrm{p}<0.01,{ }^{* *} \mathrm{p}<0.05,{ }^{*} \mathrm{p}<0.1$ 